\title{
Complete mitochondrial genome sequence of the "copper moss" Mielichhoferia elongata reveals independent nad7 gene functionality loss
}

\author{
Denis V Goruynov ${ }^{\text {Corresp., }}{ }^{1}$ ， Svetlana V Goryunova ${ }^{2}$ ， Oxana I Kuznetsova ${ }^{3}$ ， Maria D Logacheva ${ }^{1}$, Irina A \\ Milyutina ${ }^{1}$, Alina V Fedorova ${ }^{1}$, Michael S Ignatov ${ }^{3}$, Aleksey V Troitsky ${ }^{\text {Corresp. } 1}$ \\ 1 Belozersky Institute of Physico-Chemical Biology, Lomonosov Moscow State University, Moscow, Russian Federation \\ 2 Institute of General Genetics Russian Academy of Science, Moscow, Russian Federation \\ 3 Tsitsin Main Botanical Garden Russian Academy of Science, Moscow, Russian Federation \\ Corresponding Authors: Denis V Goruynov, Aleksey V Troitsky \\ Email address: denis.goryunov@mail.ru, bobr@belozersky.msu.ru
}

The mitochondrial genome of moss Mielichhoferia elongata has been sequenced and assembled with Spades genome assembler. It consists of 100,342 base pairs and has practically the same gene set and its order as in other known bryophyte chondriomes. The genome contains 66 genes including three rRNAs, 24 tRNAs, and 40 conserved mitochondrial proteins genes. Unlike the majority of previously sequenced bryophyte mitogenomes, it lacks the functional nad7 gene. The phylogenetic reconstruction and scrutiny analysis of the primary structure of nad7 gene carried out in this study suggest its independent pseudogenization in different bryophyte lineages. Evaluation of the microsatellite (simple sequence repeat) content of the Mielichhoferia elongata mitochondrial genome indicates that it could be used as a tool in further studies as a phylogenetic marker. The strongly supported phylogenetic tree presented here, derived from 33 protein coding sequences of 40 bryophyte species is consistent with other reconstructions based on a number of different data sets. 
1

2

3

4

\section{Complete mitochondrial genome sequence of the "copper moss" Mielichhoferia} elongata reveals independent nad 7 gene functionality loss.

Denis V. Goryunov ${ }^{1}$, Svetlana V. Goryunova ${ }^{2}$, Oxana I. Kuznetsova ${ }^{3}$, Maria D. Logacheva ${ }^{1}$, Irina A. Milyutina ${ }^{1}$, Alina V. Fedorova ${ }^{1}$, Michael S. Ignatov ${ }^{3}$, Aleksey V. Troitsky ${ }^{1}$

${ }^{1}$ Belozersky Institute of Physico-Chemical Biology, Lomonosov Moscow State University, Moscow, Russian Federation

${ }^{2}$ Institute of General Genetics Russian Academy of Science, Moscow, Russian Federation ${ }^{3}$ Tsitsin Main Botanical Garden Russian Academy of Science, Moscow, Russian Federation

Corresponding authors:

Aleksey V. Troitsky ${ }^{1}$

e-mail bobr@belozersky.msu.ru

Denis V. Goryunov ${ }^{1}$

e-mail: denis.goryunov@mail.ru 


\section{ABSTRACT}

The mitochondrial genome of the moss Mielichhoferia elongata has been sequenced and assembled with the Spades genome assembler. It consists of 100,342 base pairs and has practically the same gene set and order as reported for other known bryophyte chondriomes. It is the smallest known mitogenome among bryophytes. The genome contains 66 genes including three rRNAs, 24 tRNAs, and 39 conserved mitochondrial proteins genes. Unlike the majority of previously sequenced bryophyte mitogenomes, this mitogenome lacks a functional nad7 gene. The phylogenetic reconstruction and scrutiny analysis of the primary structure of the nad7 gene carried out in this study suggest an independent pseudogenization in different bryophyte lineages. Evaluation of the microsatellite (simple sequence repeat) content of theMielichhoferia elongata mitochondrial genome indicates that it could be used as a tool in further studies as a phylogenetic marker. The strongly supported phylogenetic tree presented here, derived from 33 protein coding sequences of 40 bryophyte species is consistent with other reconstructions based on a number of 31 different data sets. 

evolution that shows a dominance of the gametophyte stage in the life cycles. These nonvascular pioneers of land plants first acquired adaptations that enabled the transition from aquatic to terrestrial habitats. Mosses (Bryophyta), branched off from the stem of the Embryophyta phylogenetic tree after the Marchantiophyta and before the separation of the Anthocerotophyta 
60

61

mosses" (Antonovics et al., 1971; Chopra \& Kumra, 1988; Persson, 1948, 1956; Shaw, 1987, 1989). M. elongata Homsch. (Shaw, 2000) and the closely related Mielichhoferia mielichhoferiana (Funck.) Loeske are among the species that are highly tolerant and largely restricted to substrates enriched in copper. These species are widely distributed around the globe, but are always rare. They grow in habitats rich in copper (often associated with other metals) and inorganic sulfides, which results in a very low $\mathrm{pH}$. These habitats represent areas damaged by mining (mine waste tailings) or metal-rich rocks. The heavy metal tolerance mechanisms are not well understood and apparently vary across species. Metals are adsorbed by the cell walls and are accumulated in cells (Antonovics et al., 1971; Antreich, Sassmann \& Lang, 2016; Brown, 1982; Meharg, 2005; Tyler, 1990).

Knowledge of the sequence of the mitochondrial genome of $M$. elongata will be useful both for finding an appropriate taxonomic treatment for the taxa and for population studies within the Mielichhoferia. The latter studies are particularly important in light of the disruptive character of the habitat area, the rarity of these species, and ongoing habitat damage.

\section{MATERIALS AND METHODS}

\section{Sample collection and DNA isolation}

The M. elongata samples were collected from July 12-17, 2011 in the area near Mus-Khaya Peak (62³1'-36'N, 140 $56^{\prime}-141^{\circ} 07^{\prime}$ E) Republic of Sakha (Yakutia) and deposited in MHA, the Herbarium of the Main Botanical Garden Russian Academy of Science, Moscow (Ignatova et al., 2011). This moss was originally identified in a cited paper as Mielichhoferia mielichhoferiana. However, a subsequent analysis of the nuclear rDNA 5.8S-ITS 2 region attributed this plant to that of morphologically hardly distinguishable M. elongata (Fig. S1). Rocks in the area are especially rich in $\mathrm{MnS}$, with other heavy metals ( $\mathrm{Pb}, \mathrm{Sn}, \mathrm{As}, \mathrm{Zn}, \mathrm{Ag}$, etc., usually as sulfides) present in high concentrations. Consequently, many brooks have very acidic water and sulfurr deposits along them. Siderite (iron carbonate) forms red outcrops ('Red rocks') 
86

87

88

89

90

91

92

93

94

95

102

103

104

105

106

107

108

109

110

rich in iron and is always enriched with other heavy metals. When the outcrops are dry, $M$. elongata is the only moss that grows on this substrate or at least it is the only particularly abundant one.

DNA was extracted from specimens in the herbarium collection that had been gathered with a minimal soil amount and dried using ordinary herbarium techniques (in a paper envelope, under a tent, in the shade for several days until dry), and then stored in the herbarium at room temperature. A Nucleospin Plant DNA Kit (Macherey Nagel, Germany) was used for total DNA extraction from whole shoots of plants according to the manufacturers' protocol. A yield of about $2 \mu \mathrm{g}$ DNA was obtained according to measurements determined with a Qubit fluorometer (Invitrogen, USA).

\section{Library preparation and sequencing}

A 500 ng sample of genomic DNA was fragmented using a Covaris S220 sonicator (Covaris, USA) and a library was prepared using TruSeq DNA sample preparation kit (Illumina, USA). The concentration of the prepared library was measured with the Qubit fluorometer (Invitrogen, USA) and qPCR and fragment length distribution was determined with Bioanalyzer 2100 (Agilent). The library was diluted to $10 \mathrm{pM}$ and used for cluster generation on a cBot instrument with TruSeq PE Cluster Kit v3 reagents (Illumina, USA). Sequencing was performed on a HiSeq2000 sequencer with read length of 101 from both ends of the fragments. About 6 million read pairs were obtained.

\section{Mitogenome assembly and annotation}

Raw sequencing reads were preprocessed with Trimmomatic software (Bolger, Lohse \& Usadel, 2014) to remove adapters and low-quality data from further analysis. The whole genome assembly was then accomplished using the Spades assembler (Bankevich et al., 2012). A Blast database was generated from the assembled contigs, and a Blast search was performed against the Physcomitrella patens MG sequence (Terasawa et al., 2007) using the standalone NCBI 
111

112

113

114

115

116

117

118

119

120

121

122

123

124

125

126

127

BLAST-2.2.29+ (Altschul et al., 1990). The longest hit was the M. elongata complete MG.

Iterative mapping was carried out using Geneious R10 software (https:/www.geneious.com;

Kearse et al., 2012) to verify the assembled genome. The resulting sequence had almost 100X coverage depth. The correctness of the genome boundaries was verified by PCR amplification followed by Sanger sequencing. Initial reads mapping to the genome sequence with Bowtie 2 (Lingmead et al., 2009) was applied as an additional genome structure verification step.

Genome annotation based on sequence similarity was performed using Geneious software. The MG sequence of Bartramia pomiformis which gave a maximum score in a BLAST search against a $M$. elongata MG query was applied as a reference. The annotated genome sequence was submitted to GenBank (accession number: MF417767). A circular genome map was drawn using the CGView Server (Grant \& Stothard, 2008;

http://stothard.afns.ualberta.ca/cgview server).

\section{SSR analysis}

Simple sequence repeats (SSRs) were detected and located in the MG of $M$. elongata using GMATo v1.2 software (Wang, Lu \& Luo, 2013).

\section{Phylogenomic analysis}

Phylogenetic reconstruction was conducted by selecting only functional protein-coding sequences (CDS) present in MGs of all bryophytes under invesigation. A total of 33 of these CDS are known, including atp1, atp4, atp6, atp8, atp9, cob, cox1, cox2, cox3, nad1, nad2, nad3, nad4, nad4L, nad5, nad6, nad9, rpL2, rpL5, rpL6, rpL16, rps1, rps2, rps4, rps7, rps11, rps12, rps 13, rps 14, rps19, sdh3, sdh4, and tatC. . These, were extracted from the MG sequences of 39 mosses and the liverwort Treubia lacunose available in GenBank (www.ncbi.nlm.nih.gov), and the M. elongata sequenced in this work. The GenBank files were imported into Geneious R10 
135

136

137

and merged to export a fasta dataset file. All sequences from this dataset were aligned using the default option implemented in MAFFT (Katoh \& Standley, 2013). The final alignment was adjusted manually in BioEdit 7.2.5. (Hall, 1999).

Phylogenetic reconstruction was performed using the Bayesian method with the program MrBayes v3.2.6 (Ronquist et al., 2012). For Bayesian analyses, we used a parallel MPI version of MrBayes (Altekar et al., 2004). Two simultaneous runs of Metropolis Coupled Markov Chain Monte Carlo (MC3), both with one cold and seven heated chains were performed for 10 million generations. Two starting trees were chosen randomly. The General Time Reversible evolutionary model $(\mathrm{GTR}+\mathrm{I}+\mathrm{G})$ with 4 rate categories was used. Posterior probabilities (PP) for trees and parameters were saved every 1000 generations and parameters for each data partition were sampled independently from each other; the first $25 \%$ of the trees was discarded in each run. Bayesian PPs were used as branch support values.

\section{RESULTS}

\section{Structure of the $M$. elongata mitogenome}

The MG of M. elongata is 100,342 bp in length and has a typical circular structure (Figure 1). The nucleotide composition of this genome has a GC content of 39.8\%. The MG of M. elongata contains 66 genes including genes for 3 rRNAs (rrn18, rrn26, and rrn5), 24 tRNAs, and 39 conserved mitochondrial proteins (15 ribosomal proteins, $4 \mathrm{ccm}$ proteins, 8 nicotinamide adenine dinucleotide dehydrogenase subunits, 5 ATPase subunits, 2 succinate dehydrogenase subunits, 1 apocytochrome b, 3 cytochrome oxidase subunits, and 1 twin-arginine translocation complex subunit). Besides the functional genes, a single pseudogene, nad7, resides in the genome (Table $1)$.

\section{Structure of nad7 gene in bryophytes}

The lack of a functional gene copy of the nad7 gene has been reported previously in the MG of hornworts and the majority of liverworts (Groth-Malonek et al., 2007; Li et al. 2009; Xue et 
160

161

162

163

164

165

166

167

168

169

170

171

172

173

174

175

176

177

178

179

180

181

182

183

184

185

al., 2010). Evolution and losses of the functionality of the gene copies within mosses also deserve special attention and scrutiny. Pseudogenization of the nad7 gene is currently described for Tetraphis pellucida and Buxbaumia aphylla (Bell et al., 2014; Liu, Medina \& Goffinet, 2014), whereas all other sequenced bryophyte MGs have a functional gene, that consists of three exons separated by two introns. The only known exception is the nad7 locus structure in MG of Hypnum imponens (NC 024516), its functional gene consists of only two exons and one intron sequences. The intron 2 of the gene was lost and exon 2 and exon 3 were merged together in one exon sequence. The low conservation of the pseudogene sequences has created difficulties in constructing a reliable nucleotide alignment and unambiguously judging whether exons 2 and 3 are completely deleted in either these chondriomes or whether some exon remnants are still preserved. We performed a Tblastn search of these exons amino acid sequence of the nad7 gene in T. pellucida and B. aphylla and confirmed the absence of exon 2 in B. aphylla and exon 3 in both species. The same finding is evident from Figure S2 with the alignment of nad7 from $B$. aphylla, T. pellucida, M. elongata, and six other moss species. It agrees with the earlier data provided by Bell et al. (2014) on the structure of the T. pellucida MG. In addition, B. aphylla and T. pellucida pseudogenes have deletions in the sequences of the first gene exon, although at different locations. The main difference in the nad7 pseudogene primary structure in these bryophytes is two deletions in the sequence of exon 2 in B. aphylla whereas T. pellucida has an intact exon 2 sequence. By contrast, the nad7 pseudogene of M. elongata completely lacks the second exon and has intact exon 1 sequence and exon 3 with frame shift mutation as a result of 2 bp insertion located at $190 \mathrm{bp}$ from 5' end of the exon (Figure 2).

\section{SSR analysis of the $M$. elongata mitochondrial genome}

Following more stringent criteria (Zhao et al., 2016) of perfect SSR locus identification (minimal number of repeating units $\geq 10$ for mononucleotides, $\geq 5$ for dinucleotides, $\geq 4$ for trinucleotides, and $\geq 3$ for tetra-, penta- and hexanucleotides) 73 SSR loci were identified in the MG of M. elongata (Table 2 and Figure 3). Most microsatellites refer to mono- and dinucleotides 
186

187

188

189

190

191

192

193

194

195

196

197

198

199

200

201

202

203

204

205

206

207

208

209

210

classes (35 and 28 loci, respectively). Trinucleotides are the least frequent SSRs group in the genome (one locus). No hexanucleotide microsatellite repeats occur in the genome. Among all the SSRs, $87.67 \%$ are composed only of A/T bases. The total length of the SSR loci is $852 \mathrm{bp}$, which comprises approximately $0.85 \%$ of the genome length.

\section{Phylogenetic analysis}

The alignment of 33 mitochondrial protein CDS of 40 moss taxa and hepatic Treubia lacunosa (Haplomitriopsida, Treubiidae, Treubiales, Treubiaceae) consists of 24,827 positions. The Bayesian phylogenetic tree inferred from this data with the hepatic T. lacunosa as an outgroup is shown in Figure 4. Most nodes of the tree have very high PP supports. Two exceptions are two nodes among the Orthotrichaceae.

\section{DISCUSSION}

We performed sequencing and analysis of the MG of M. elongata, a rare "copper moss" with an ambiguous taxonomic status. The-MG size significantly varies even among closely related flowering plants (Allen et al., 2007; Alverson et al., 2010; Cho et al., 2004; Sloan et al., 2010; 2012), but it is extremely stable in bryophytes (Liu, Medina \& Goffinet, 2014). The MG of $M$. elongata is $383 \mathrm{bp}$ smaller than the genome of B. aphylla (Liu, Medina \& Goffinet, 2014), which to date is the smallest MG among bryophytes. However, the MG of M. elongata contains the same set of genes and a similar genome structure to that of other mosses. The only difference is a pseudogenization of the nad7 gene.

This locus encodes subunit 7 of NADH dehydrogenase (NDH-1 or complex I of the mitochondrial electron transfer chain) is located on the inner mitochondrial membrane and plays an important role in oxidative phosphorylation process (Bonen et al., 1994). NDH-1 is a quite complicated protein complex, consisting of approximately 30-40 subunits (Kerscher et al., 2008). The majority of the subunits are encoded in nuclear genome, but several proteins of the complex 
211 are specified by mitochondrial genes (Bonen et al., 1994).

212 Although the MGs of the Bryophyta are highly stable in terms of their gene content, there 213 are two other mosses, $B$. aphylla and $T$. pellucida that lack the intact open reading frame (ORF) 214 of the nad7 gene in their MGs (Bell et al., 2014; Liu, Medina \& Goffinet, 2014). In our study, we 215 found that the exon structure of nad7 pseudogene of M. elongata differs substantially when 216 compared with that of the MGs of B. aphylla and T. pellucida. Taking into account the close 217 location of the later on the constructed a phylogenetic tree (Fig. 4) and the extremely distant 218 position of $M$. elongata relative to them, the loss of the functionality of the nad7 gene can be 219 concluded to have occurred at least twice during the evolutionary history of the mosses.

Intact nad7 genes were found in the MGs of different angiosperms clades (Adams \& Palmer, 2003 ) and in representatives of hornworts, lycophytes, ferns and gymnosperms (Guo et al., 2017; Li et al., 2009; Xue et al., 2010). However several exceptions were noted in different evolutionary lineages. Therefore, the absence of a functional nad7 gene was noted in the MG of Nicotiana sylvestris cytoplasmic male sterile (CMS) mutants (Pla et al., 1995) and in the lycophyte Huperzia squarrosa (Liu et al., 2012). In the liverwort Marchantia polymorpha, a functional nad7 gene was transferred from the MG to nucleus, but the pseudogene was preserved in the MG (Kobayashi et al., 1997). Pseudogenization of nad7 was observed in 11 other liverwort groups, whereas the intact gene was found in Haplomitrium mnioides MG (GrothMalonek et al., 2007). This discovery suggested a basal placement of the taxon among liverworts. Overall, pseudogenization of nad7 may have occurred independently in different unrelated lineages of embryophytes.

A total of 73 simple sequence repeats (SSRs, microsatellites) loci were identified in the MG of M. elongata. SSRs are common in plant and animal genomes and could play an important role in gene functioning ( $\mathrm{Li}$ et al., 2004). Besides the occurrence of the SSR loci in nuclear genomes, microsatellite repeats are present in plastids and MGs as well (Kumar, Kapil, \& Shanker, 2014; Sablok, 2015). However, to date, it is much less known about distribution and functions of 
237

238

239

240

241

242

243

244

microsatellites in bryophyte genomes. SSR loci are usually characterized by high mutation rate, and therefore actively used as molecular markers in population genetics surveys (Zalapa et al., 2012). Molecular markers based on organellar microsatellites have been used successfully for phylogeny reconstruction at the genus taxonomic level and for intraspecific variation analysis (Ishii, Mori \& Ogihara, 2001; Nishikawa, Vaughan \& Kadowaki, 2005). The SSR loci revealed in the MG of M. elongata could therefore be further investigated to obtain informative markers for using in monitoring programs for Mielichhoferia species. That is especially important due to the disruptive character of the habitat area, the rarity of the species, and ongoing habitat damage. M. elongata represents a separate branch on a phylogenetic tree within the Bryidae and is closest to the Hypnales/Ptychomniales/Orthotrichales group. However, the absence of a MG sequence for the Mniaceae and Bryaceae representatives preclude clarification of the taxonomic position of-Mielichhoferia. The phylogenetic tree depicted in Figure 4 inferred from 33 mitochondrial CDSes of 40 mosses species with liverwort as an outgroup, is consistent with other reconstructions based on 14-17 plastid genes from 43 moss species representing the major lineages summarized by Chang, Sean \& Graham (2013), and based on 41 concatenated mitochondrial protein-coding genes from19 Bryophyta species (Liu et al., 2014). Although plant mitochondrial sequences evolve slowly (Palmer \& Herbon, 1988), phylogenomic analyses can be effective for bryophytes taxa of both lower and higher ranks. Of course, the remarks of Liu et al. (2014) and other earlier authors should be kept in minds; namely, that even high support does not guarantee that an inferred phylogeny is approaching the true evolutionary history.

\section{CONCLUSION}

This study provides the complete MG sequence of the "copper moss" Mielichhoferia elongata consisting of 100,342 base pairs. It is the smallest known mitochondrial genome among bryophytes and non-parasitic tracheophytes. M. elongata is a moss with very specific requirements regarding environmental conditions; in particular, it is mostly confined to heavy metals enriched substrates. Although the MG has the same gene set as that found within previously studied mosses and does not demonstrate any special features associated with high 
264

265

266

267

268

269

270

271

272

273

274

275

276

277

278

279

280

281

282

283

284

285

286

287

288

289

290

heavy metal tolerance, it lacks a functional nad7 gene. Based on the phylogeny reconstruction data and exon structure analysis of the gene, it has been deduced, that nad7 pseudogenization took place independently not once in moss evolution. The phylogenetic tree presented in this study, inferred from the 33 mitochondrial CDS of 41 bryophyte species is consistent with the reconstructions made in earlier studies.

\section{ACKNOWLEDGEMENTS}

We thank reviewers and the editors for their insightful suggestions and comments on the paper. We are grateful to Paul Stothard for assistance in genome map preparation.

\section{REFERENCES}

Adams KL, Palmer JD. 2003. Evolution of mitochondrial gene content: gene loss and transfer to the nucleus. Molecular Phylogenetics and Evolution 29(3):380-395 DOI 10.1016/S10557903(03)00194-5.

Allen JO, Fauron CM Minx P, Roark L, Oddiraju S, Lin GN, Meyer L, Sun H, Kim K, Wang C, Du F, Xu D, Gibson M, Cifrese J, Clifton SW, Newton KJ. 2007. Comparisons among two fertile and three male-sterile mitochondrial genomes of maize. Genetics 177(2):1173-1192 DOI 10.1534/genetics.107.073312.

Altekar G, Dwarkadas S, Huelsenbeck JP, Ronquist F. 2004. Parallel Metropolis coupled Markov chain Monte Carlo for Bayesian phylogenetic inference. Bioinformatics 20(3):407415 DOI 10.1093/bioinformatics/btg427.

Altschul SF, Gish W, Miller W, Myers EW, Lipman DJ. 1990. Basic local alignment search tool. Journal of Molecular Biology 215(3):403-410 DOI 10.1016/S0022-2836(05)80360-2.

Alverson AJ, Wei XX, Rice DW, Stern DB, Barry K, Palmer JD. 2010. Insights into the evolution of mitochondrial genome size from complete sequences of Citrullus lanatus and Cucurbita pepo (Cucurbitaceae). Molecular Biology and Evolution 27(6):1436-1448 DOI:10.1093/molbev/msq029.

Antonovics J, Bradshaw AD, Turner RG. 1971. Heavy metal tolerance in plants. Advances in 
291

292

293

294

295

296

297

298

299

300

301

302

303

304

305

306

307

308

309

310

311

312

313

314

315

316

317

\section{Ecological Research 7:1-85 DOI https://doi.org/10.1016/S0065-2504(08)60202-0.}

Antreich S, Sassmann S, Lang I. 2016. Limited accumulation of copper in heavy metal adapted mosses. Plant Physiology and Biochemistry 101:141-148. DOI http://dx.doi.org/10.1016/j.plaphy.2016.02.005.

Bankevich A, Nurk S, Antipov D, Gurevich AA, Dvorkin M, Kulikov AS, Lesin VM, Nikolenko SI, Pham S, Prjibelski AD, Pyshkin AV, Sirotkin AV, Vyahhi N, Tesler G, Alekseyev MA, Pevzner PA. 2012. SPAdes: a new genome assembly algorithm and its applications to singlecell sequencing. Journal of Computational Biology 19(5):455-477 DOI $10.1089 / \mathrm{cmb} .2012 .0021$.

Bell NE, Boore JL, Mishler BD, Hyvönen J. 2014. Organellar genomes of the four-toothed moss, Tetraphis pellucida. BMC Genomics 15(1):383 DOI 10.1186/1471-2164-15-383.

Bolger AM, Lohse M, Usadel B. 2014. Trimmomatic: a flexible trimmer for Illumina sequence data. Bioinformatics 30(15):2114-2120 DOI 10.1093/bioinformatics/btu170.

Bonen L, Williams K, Bird S, Wood C. 1994. The NADH dehydrogenase subunit 7 gene is interrupted by four group II introns in the wheat mitochondrial genome. Molecular and General Genetics MGG 244:81-89 DOI https://doi.org/10.1007/BF00280190

Brown DH. 1982. Mineral nutrition. In: Smith AJE. (Ed.), Bryophyte Ecology 383-444. London N.-Y, Chapman and Hall pp.511. DOI 10.1007/978-94-009-5891-3.

Chang Y, Sean W. Graham SW. 2013. Patterns of clade support across the major lineages of moss phylogeny. Cladistics 30(6):590-606 DOI 10.1111/cla.12066.

Cho Y, Mower JP, Qiu YL, Palmer JD. 2004. Mitochondrial substitution rates are extraordinarily elevated and variable in a genus of flowering plants. Proceedings of the National Academy of Sciences of the United States of America 101(51):17741-17746 DOI

$$
\text { 10.1073/pnas.0408302101. }
$$

Chopra RN, Kumra PK. 1988. Biology of Bryophytes. New York: Wiley \& Sons.

Grant JR, Stothard P. 2008. The CGView Server: a comparative genomics tool for circular genomes. Nucleic Acids Research 36:W181-W18 DOI 10.1093/nar/gkn179. 
318 Groth-Malonek M, Wahrmund U, Polsakiewicz M, Knoop V. 2007. Evolution of a pseudogene: 319 exclusive survival of a functional mitochondrial nad7 gene supports Haplomitrium as the 320 earliest liverwort lineage and proposes a secondary loss of RNA editing in Marchantiidae. Molecular Biology and Evolution 24(4):1068-1074 DOI 
Markowitz S, Duran C, Thierer T, Ashton B, Meintjes P, Drummond A. 2012. Geneious

Basic: an integrated and extendable desktop software platform for the organization and analysis of sequence data. Bioinformatics 28(12):1647-1649 DOI 10.1093/bioinformatics/bts 199 .

Kerscher S, Dröse S, Zickermann V, Brandt U. 2008. The three families of respiratory NADHdehydrogenases. In: Schäfer G., Penefsky HS. (eds) Bioenergetics. Results and Problems in Cell Differentiation 45:185-222.

Kimura M. 1980 A simple method for estimating evolutionary rates of base substitutions through comparative studies of nucleotide sequences. Journal of Molecular Evolution. 16:111-120.

Kobayashi Y1, Knoop V, Fukuzawa H, Brennicke A, Ohyama K. 1997. Interorganellar gene transfer in bryophytes: the functional nad7 gene is nuclear encoded in Marchantia polymorpha. Molecular and General Genetics MGG 265(5):589-592.

Kumar M, Kapil A, Shanker A. 2014. MitoSatPlant: Mitochondrial microsatellites database of viridiplantae. Mitochondrion Part B November 334-337 DOI https://doi.org/10.1016/j.mito.2014.02.002

Li Y-C, Korol AB, Fahima T, Nevo E. 2004. Microsatellites within genes: structure, function, and evolution. Molecular Biology and Evolution 21(6):991-1007 DOI https://doi.org/10.1093/molbev/msh073.

Li L, Wang B, Liu Y, Qiu Y-L. 2009. The complete mitochondrial genome sequence of the hornwort Megaceros aenigmaticus shows a mixed mode of conservative yet dynamic evolution in early land plant mitochondrial genomes. Journal of Molecular Evolution 68:665678 DOI 10.1007/s00239-009-9240-7.

Lingmead B, Trapnell C, Pop M, Salzberg SL. 2009.Ultrafast and memory-efficient alignment of short DNA sequences to the human genome. Genome Biology 10(3):R25 DOI 10.1186/gb2009-10-3-r25.

Liu Y, Cox CJ, Wang W, Goffinet B. 2014. Mitochondrial phylogenomics of early land plants: 
372

373

374

375

376

377

378

379

380

381

382

383

384

385

386

387

388

389

390

391

392

393

394

395

396

397

398

mitigating the effects of saturation, compositional heterogeneity, and codon-usage bias. Systematic Biology 63(6):862-878 DOI 10.1093/sysbio/syu049.

Liu Y, Medina R, Goffinet B. 2014. 350 million years of mitochondrial genome stasis in mosses, an early land plant lineage. Molecular Biology and Evolution 31(10):2586-2591 DOI 10.1093/molbev/msu199.

Liu Y, Wang B, Cui P, Li L, Xue J-Y, Yu J, Qiu Y-L. 2012. The Mitochondrial Genome of the Lycophyte Huperzia squarrosa: The Most Archaic Form in Vascular Plants. PLos One 7(4) DOI https://doi.org/10.1371/journal.pone.0035168.

Meharg AA. 2005 Mechanisms of plant resistance to metal and metalloid ions and potential biotechnological applications. Plant and Soil 274:163-174 DOI 10.1007/s11104-004-0262-z.

Nishikawa T, Vaughan DA, Kadowaki K. 2005. Phylogenetic analysis of Oryza species, based on simple sequence repeats and their flanking nucleotide sequences from the mitochondrial and chloroplast genomes. Theoretical and Applied Genetics 110(4):696-705 DOI 10.1007/s00122-004-1895-2.

Palmer JD, Herbon LA. 1988. Plant mitochondrial DNA evolved rapidly in structure, but slowly in sequence. Journal of Molecular Evolution 28(1-2):87-97. DOI http://dx.doi.org/10.1007/BF02143500.

Persson H. 1948. On the discovery of Merceya ligulata in the Azores with a discussion of the socalled "copper mosses." Revue Bryologique et Lichenologique. 17:75-88.

Persson H.1956. Studies in "copper mosses." The Journal of the Hattori Botanical Laboratory 17:1-18.

Pla M, Mathieu C, De Paepe R, Chétrit P, Vedel F. 1995. Deletion of the last two exons of the mitochondrial nad7 gene results in lack of the NAD7 polypeptide in a Nicotiana sylvestris CMS mutant. Molecular and General Genetics MGG 248(1):79-88.

Qiu, YL, Li L, Wang B, Chen Z, Knoop V, Groth Malonek M, Dombrovska O, Lee J, Kent L, Rest J, Estabrook GF, Hendry TA, Taylor DW, Testa CM, Ambros M, Crandall Stotler B, Duff RJ, Stech M, Frey F, Quandt D, Davis CC. 2006. The deepest divergences in land 
399

400

401

402

403

404

405

406

407

408

409

410

411

412

413

414

415

416

417

418

419

420

421

422

423

424

425

plants inferred from phylogenomic evidence. Proceedings of the National Academy of Sciences of the United States of America 103:15511-15516 DOI 10.1073/pnas.0603335103.

Ronquist F, Teslenko M, van der Mark P, Ayres DL, Darling A, Höhna S, Larget B, Liu L, Suchard MA, Huelsenbeck JP. 2012. MrBayes 3.2: Efficient Bayesian phylogenetic inference and model choice across a large model space. Systematic Biology 61(3): 539-542. DOI 10.1093/sysbio/sys029.

Sablok G, Padma Raju GV, Mudunuri SB, Prabha R, Singh DP,Baev V, Yahubyan G,Ralph PJ, La Porta N. 2015. ChloroMitoSSRDB 2.00: more genomes, more repeats, unifying SSRs search patterns and on-the-fly repeat detection. Database 1-10 DOI 10.1093/database/bav084.

Saitou N, Nei M. 1987. The neighbor-joining method: A new method for reconstructing phylogenetic trees. Molecular Biology and Evolution 4:406-425.

Shaw AJ. 2000. Molecular phylogeography and cryptic speciation in the mosses, Mielichhoferia elongata and M. mielichhoferiana (Bryaceae). Molecular Ecology 9:595-608 DOI 10.1046/j.1365-294x.2000.00907.x.

Shaw AJ. 2009. Mielichhoferiaceae. In: Flora of North America 28:190 DOI http://www.efloras.org/florataxon.aspx?flora_id=1\&taxon_id=20921.

Shaw J. 1987. Evolution of heavy metal tolerance in bryophytes II. An ecological and experimental investigation of the "copper moss", Scopelophila cataractae (Pottiaceae). American Journal of Botany 74(6):813-821.

Shaw J. 1989. Heavy Metal Tolerance in Plants: Evolutionary Aspects. Boca Raton, Florida: CRC Press. pp.268.

Sloan DB, Alverson AJ, Chuckalovcak JP, Wu M, McCauley DE, Palmer JD, Taylor DR. 2012. Rapid evolution of enormous, multichromosomal genomes in flowering plant mitochondria with exceptionally high mutation rates. PLOS Biology 10(1):e1001241 doi:10.1371/journal.pbio.1001241

Terasawa K, Odahara M, Kabeya Y, Kikugawa T, Sekine Y, Sato N. 2007. The mitochondrial genome of the moss Physcomitrella patens sheds new light on mitochondrial evolution in land 
426

427

428

429

430

431

432

433

434

435

436

437

438

439

440

441

442

443

444

445

446

447

448

449

450

451

452

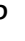

plants. Molecular Biology and Evolution 24:699-709 DOI 10.1093/molbev/msl198.

Tyler G. 1990. Bryophytes and heavy metals: a literature review. Botanical Journal of the Linnean Society 104:231-253 DOI https://doi.org/10.1111/j.1095-8339.1990.tb02220.x.

Van de Peer Y, De Wachter R. 1994. TREECON for Windows: a software package for the construction and drawing of evolutionary trees for the Microsoft Windows environment. Bioinformatics 10(5): 569-570. DOI https://doi.org/10.1093/bioinformatics/10.5.569.

Wang X, Lu P, Luo Z. 2013. GMATo: A novel tool for the identification and analysis of microsatellites in large genomes. Bioinformation 9(10):541-544 DOI $10.6026 / 97320630009541$.

Xue J-Y, Liu Y, Li L, Wang B, Qiu Y-L. 2010. The complete mitochondrial genome sequence of the hornwort Phaeoceros laevis: retention of many ancient pseudogenes and conservative evolution of mitochondrial genomes in hornworts. Current Genetics 56(1):53-61 DOI 10.1007/s00294-009-0279-1.

Zalapa JE, Cuevas H, Zhu H, Steffan S, Senalik D, Zeldin E, McCown B, Harbut R, Simon P. 2012. Using next-generation sequencing approaches to isolate simple sequence repeat (SSR) loci in the plant sciences. American Journal of Botany (99)2:193-208 DOI 10.3732/ajb.1100394.

Zhao C-X, Zhu R-L, Liu Y. 2016. Simple sequence repeats in bryophyte mitochondrial genomes. Mitochondrial DNA Part A 27(1):191-197 DOI https://doi.org/10.3109/19401736.2014.880889.

7

\section{FIGURE LEGENDS}

Figure 1. Mitogenome map of M. elongata (MF417767) consisting of 100,342 base pairs.

Figure 2. The diversity of the mitochondrial nad7 gene exon structure in mosses. The majority of the sequenced moss mitogenomes have the same type of locus structure found in Atrichum angustifolium. The black filled sections indicate absent exons (or parts of them). 
453 Figure 3. Simple sequence repeat unit length distribution in M. elongata mitogenome. $\mathrm{n}$ - the 454 numbers of base pairs $(n=1,2,3,4$, and 5$)$ in different microsatellite classes. $\mathrm{N}$ - the number of 455 loci in each SSR category.

456 Figure 4. Bayesian phylogenetic tree of 40 Bryophyta species constructed for 33 mitochondrial 457 protein coding sequences. The hepatic Treubia lacunosa was used as an outgroup. All nodes, 458 except those indicated on the tree, have maximal posterior probability values equal to 1,0 . 459 Asterisks indicate taxa with pseudogenization of nad7.

460 Figure S1. The Mielichhoferia mielichhoferiana/M. elongata evolutionary tree.

461 The phylogenetic tree based on nuclear rDNA region (5.8S rDNA-ITS 2-5'-end of 26S rDNA). 462 The alignment consists of 440 positions. The tree reconstruction was conducted in TREECON 463 software (Van de Peer \& De Wachter, 1994) using the Neighbor-Joining method (Saitou \& Nei 464 1987) with 500 bootstrap replications. Bootstrap support values $>50 \%$ are shown next to the 465 branches. The evolutionary distances were computed using the Kimura method (1980) with gaps 466 taken into account as it implemented in the TREECON package.

467 Figure S2. The alignment of nad7 genes from nine moss species.

468 The alignment was the map was created by the MAFFT program with the subsequent manual 469 checking. Only generic names of species are indicated for brevity. The full species names are 470 shown in the Figure 4. Yellow columns mark exon/intron boundaries. 
Figure 1

Mitogenome map of Mielichhoferia elongata (MF417767) consisting of 100,342 base pairs.

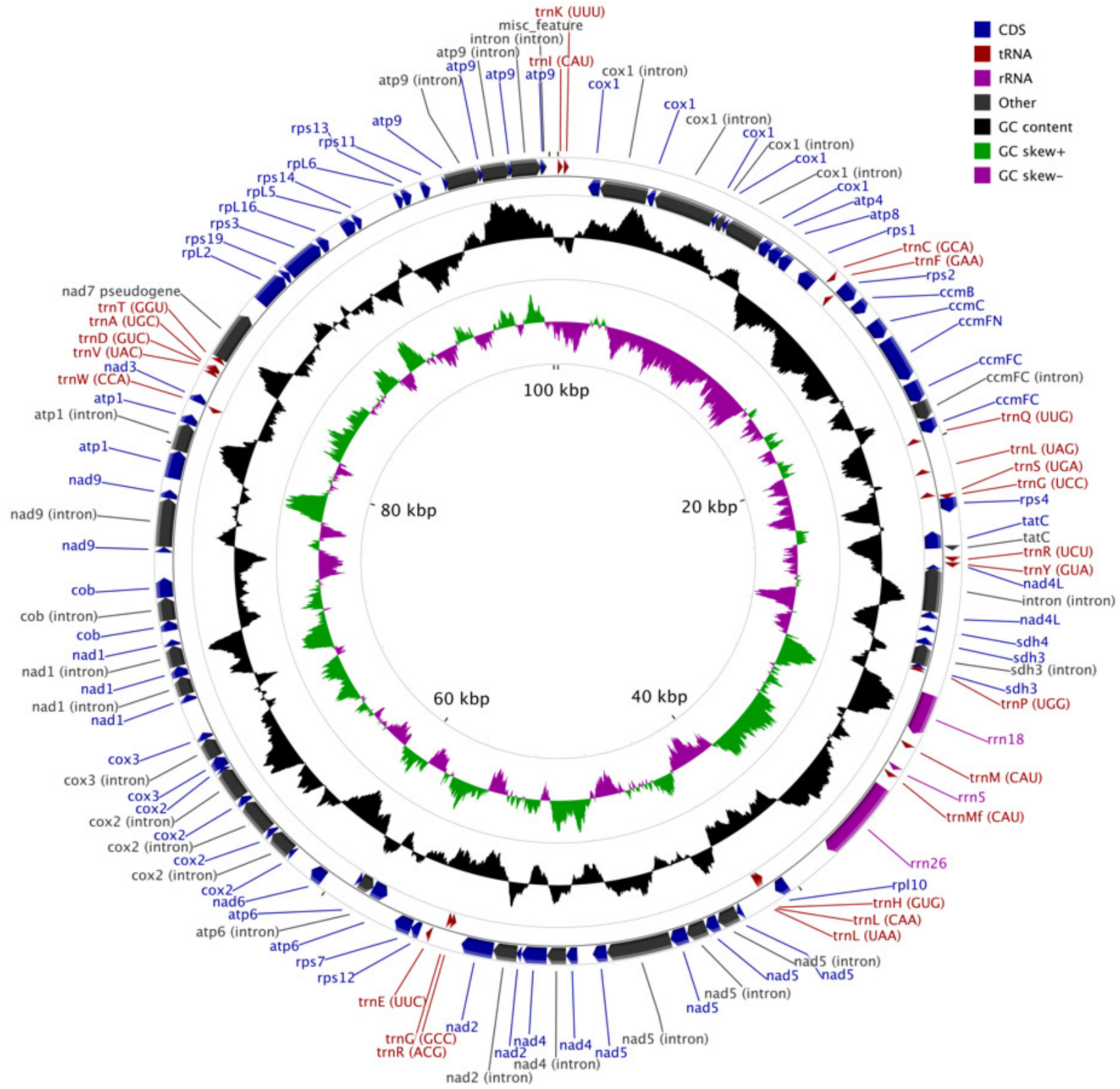




\section{Figure 2 (on next page)}

The diversity of the mitochondrial nad7 gene exon structure in mosses.

The majority of the sequenced moss mitogenomes have the same type of locus structure found in Atrichum angustifolium. The black filled sections indicate absent exons (or parts of them). 
Atrichum angustifolium

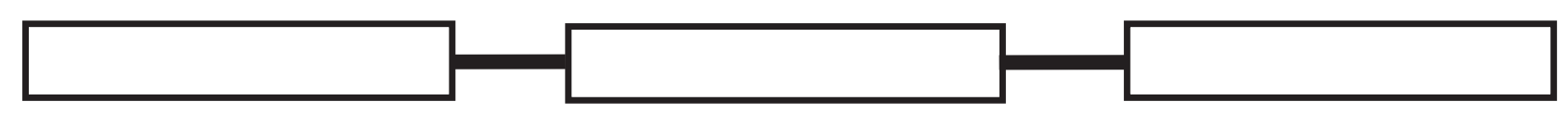

Hypnum imponens
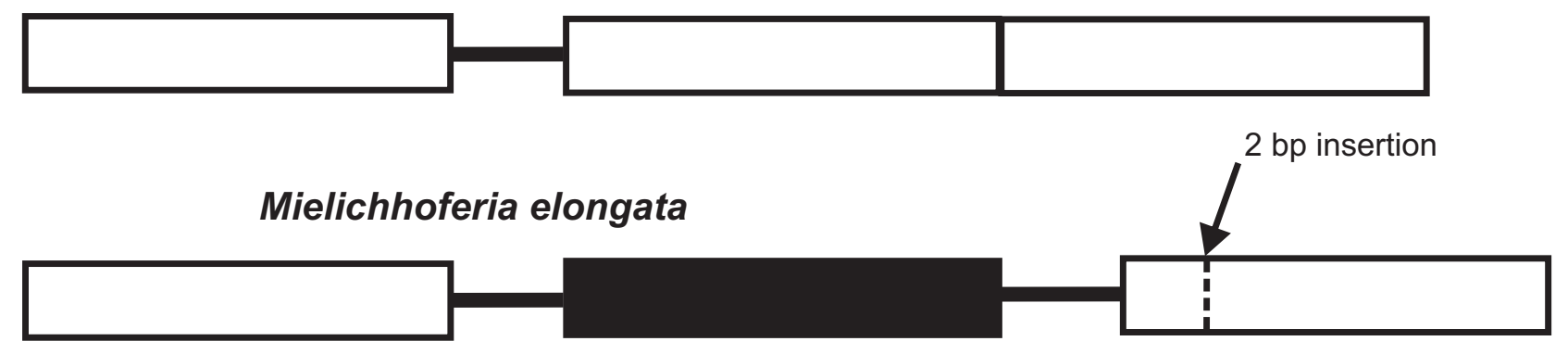

Tetraphis pellucida

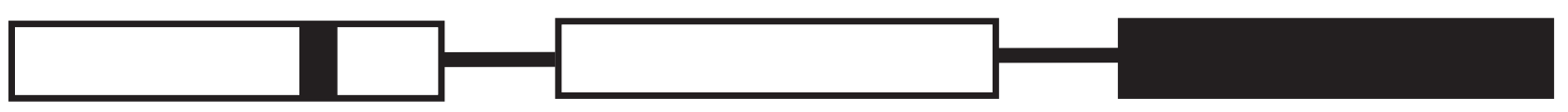

Buxbaumia aphylla

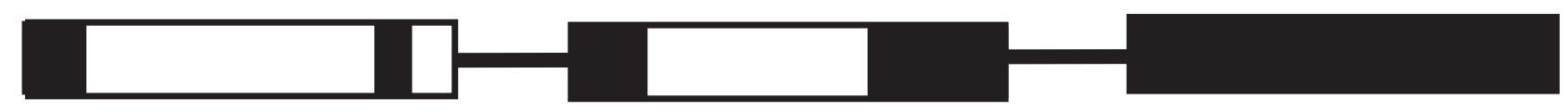

Exon 1

Exon 2

Exon 3 


\section{Figure 3 (on next page)}

Simple sequence repeat unit length distribution in M. elongata mitogenome.

$\mathrm{n}$ - the numbers of base pairs $(\mathrm{n}=1,2,3,4$, and 5$)$ in different microsatellite classes. $\mathrm{N}$ - the number of loci in each SSR category. 


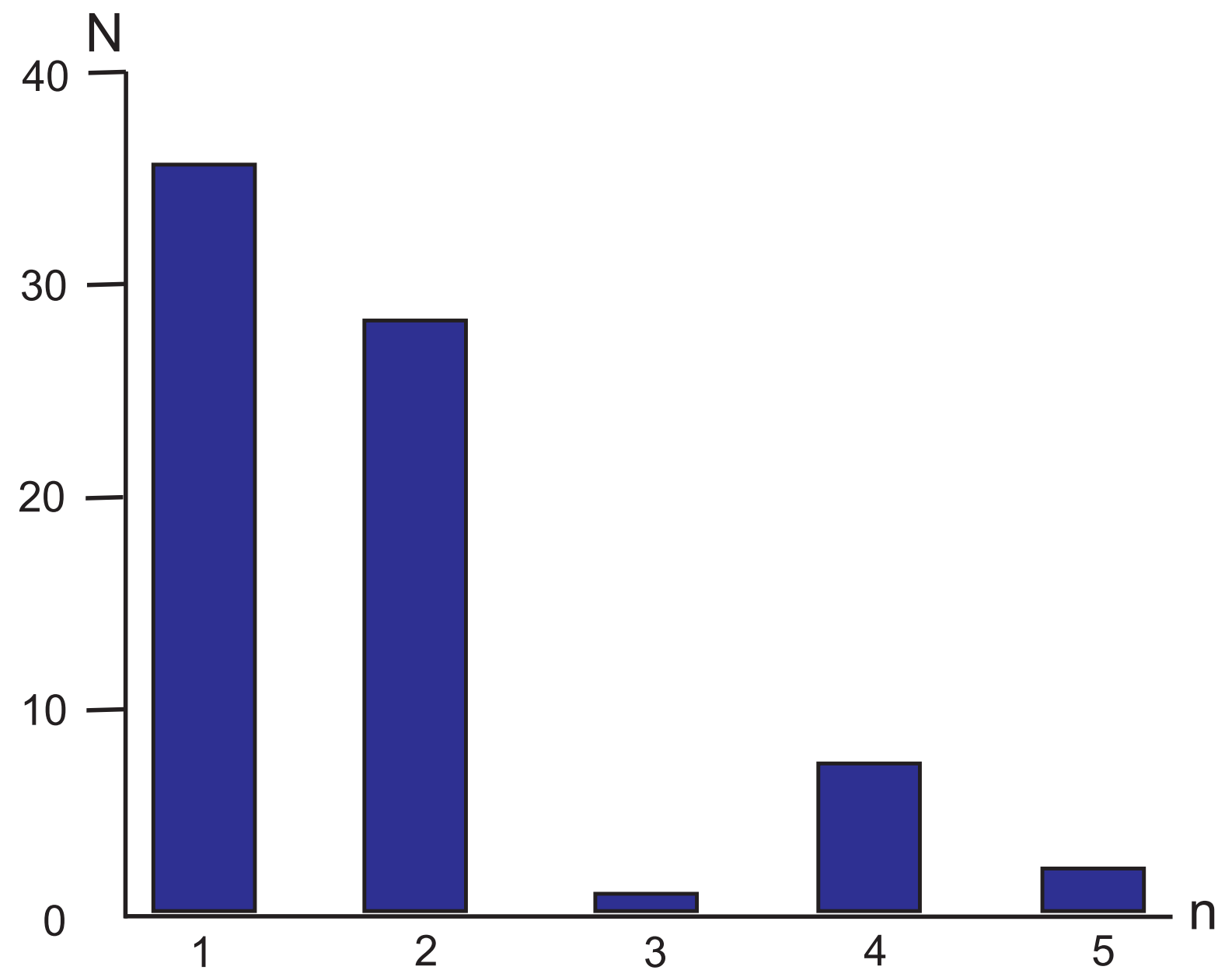


Figure 4(on next page)

Bayesian phylogenetic tree of 40 Bryophyta species constructed for 33 mitochondrial protein coding sequences.

The hepatic Treubia lacunosa was used as an outgroup. All nodes, except indicated on the tree, have maximal posterior probability values equal to 1,0 . Asterisks indicate taxa with pseudogenization of nad7. 


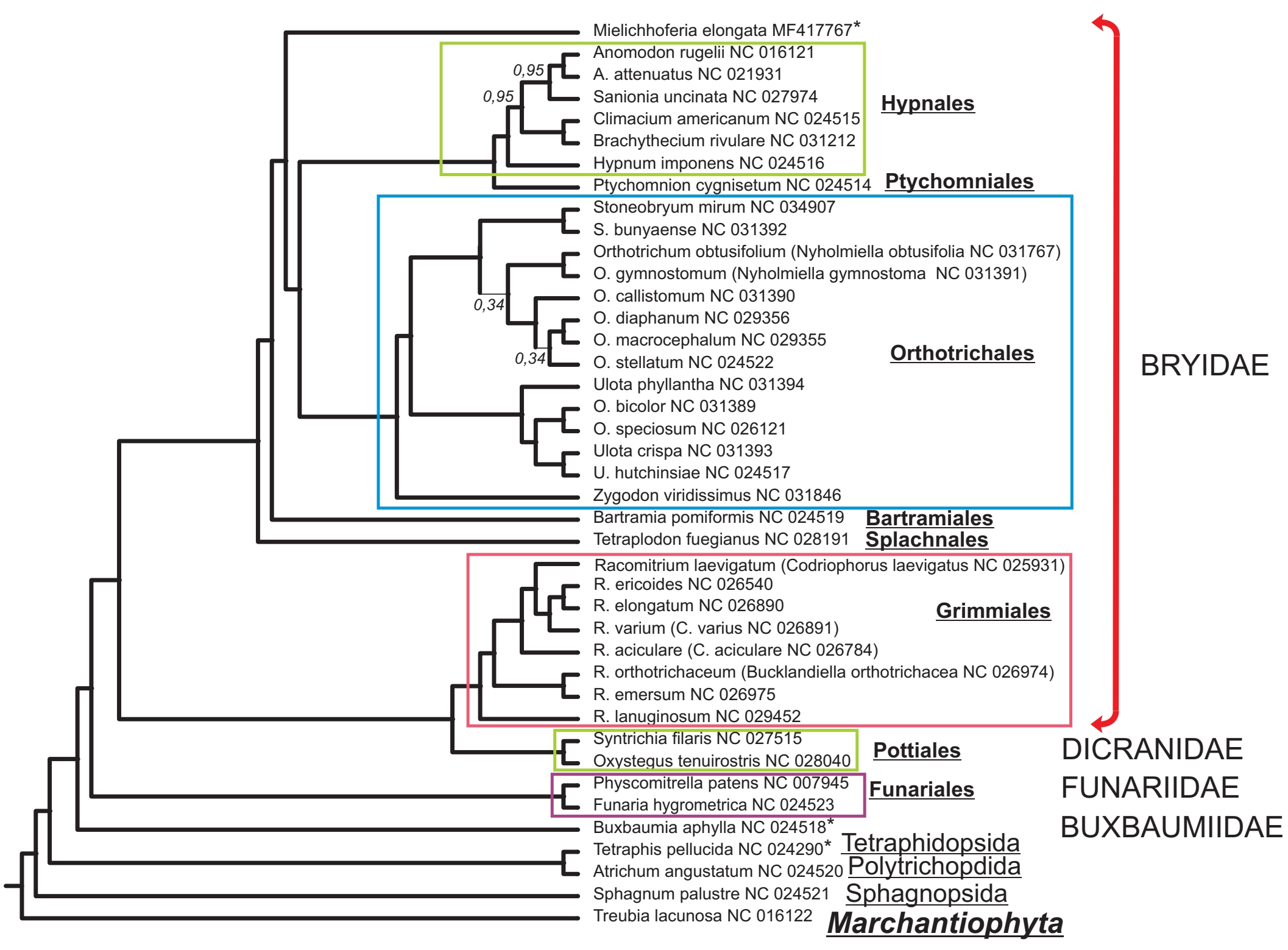




\section{Table $\mathbf{1}$ (on next page)}

Gene contents in Mielichhoferia elongata mitogenome (66 genes, one pseudogene). 
1 Table 1. Gene contents in Mielichhoferia elongata mitogenome (66 genes, one pseudogene).

\begin{tabular}{|c|c|c|c|}
\hline Category & Group of genes & Genes & $\begin{array}{l}\text { Number } \\
\text { of genes }\end{array}$ \\
\hline \multirow[b]{2}{*}{ RNA genes } & rRNAs & $r r n 18, \operatorname{rrn} 26, r r n 5$ & 3 \\
\hline & tRNAs & $\begin{array}{l}\operatorname{trn} A(U G C), \operatorname{trn} C(G C A), \operatorname{trn} D(G U C), \operatorname{trn} E(U U C), \operatorname{trn} F(G A A), \operatorname{trn} G \\
(G C C), \operatorname{trn} G(U C C), \operatorname{trn} H(G U G), \operatorname{trn} I(C A U), \operatorname{trnK}(U U U), \operatorname{trn} L \\
(C A A), \operatorname{trn} L(U A A), \operatorname{trn} L(U A G), \operatorname{trn} M(C A U), \operatorname{trn} M f(C A U), \operatorname{trn} P \\
(U G G), \operatorname{trn} Q(U U G), \operatorname{trn} R(A C G), \operatorname{trnR}(U C U), \operatorname{trn} S(U G A), \operatorname{trn} T \\
(G G U), \operatorname{trn} V(U A C), \operatorname{trn} W(C C A), \operatorname{trn} Y(G U A) \\
\end{array}$ & 24 \\
\hline \multirow{9}{*}{$\begin{array}{l}\text { conserved } \\
\text { mitochondrial } \\
\text { proteins }\end{array}$} & large ribosomal subunits & $r p l 10, r p L 16, r p L 2, r p L 5, r p L 6$ & 5 \\
\hline & small ribosomal subunits & rps 1, rps11, rps12, rps13, rps 14, rps19, rps2, rps3, rps4, rps 7 & 10 \\
\hline & cytochrome c maturation proteins & $c c m B, c c m C, c c m F C, c c m F N$ & 4 \\
\hline & $\begin{array}{l}\text { nicotinamide adenine dinucleotide } \\
\text { dehydrogenase subunits }\end{array}$ & nad1, nad2, nad3, nad4, nad4L, nad5, nad6, nad 9 & 8 \\
\hline & ATPase subunits & atp1, atp4, atp6, atp8, atp9 & 5 \\
\hline & succinate dehydrogenase subunits & $s d h 3, s d h 4$ & 2 \\
\hline & apocytochrome b & $c o b$ & 1 \\
\hline & cytochrome oxidase subunits & $\operatorname{cox} 1, \cos 2, \operatorname{cox} 3$ & 3 \\
\hline & $\begin{array}{l}\text { twin arginine translocation complex } \\
\text { subunit }\end{array}$ & tatC & 1 \\
\hline pseudogenes & & nad7pseudo & 1 \\
\hline
\end{tabular}


Table 2 (on next page)

SSR-loci of Mielichhoferia elongata mitogenome. 
1

Table 2. SSR-loci of Mielichhoferia elongata mitogenome.

3

\begin{tabular}{|l|l|l|l|l|}
\hline $\begin{array}{l}\text { Type of } \\
\text { repeat } \\
\text { unit }\end{array}$ & Motif & Repetitions & StartPos & EndPos \\
\hline mono- & $\mathrm{A}$ & 10 & 269 & 278 \\
\hline mono- & $\mathrm{A}$ & 10 & 13526 & 13535 \\
\hline mono- & $\mathrm{A}$ & 10 & 22179 & 22188 \\
\hline mono- & $\mathrm{A}$ & 10 & 25861 & 25870 \\
\hline mono- & $\mathrm{A}$ & 10 & 40307 & 40316 \\
\hline mono- & $\mathrm{A}$ & 10 & 46592 & 46601 \\
\hline mono- & $\mathrm{A}$ & 10 & 49092 & 49101 \\
\hline mono- & $\mathrm{A}$ & 10 & 52217 & 52226 \\
\hline mono- & $\mathrm{A}$ & 10 & 54565 & 54574 \\
\hline mono- & $\mathrm{A}$ & 10 & 62618 & 62627 \\
\hline mono- & $\mathrm{A}$ & 10 & 88341 & 88350 \\
\hline mono- & $\mathrm{A}$ & 10 & 91128 & 91137 \\
\hline mono- & $\mathrm{A}$ & 10 & 93879 & 93888 \\
\hline mono- & $\mathrm{A}$ & 11 & 39390 & 39400 \\
\hline mono- & $\mathrm{A}$ & 12 & 16182 & 16193 \\
\hline mono- & $\mathrm{G}$ & 10 & 98368 & 98377 \\
\hline mono- & $\mathrm{G}$ & 12 & 52784 & 52795 \\
\hline mono- & $\mathrm{G}$ & 12 & 57418 & 57429 \\
\hline mono- & $\mathrm{T}$ & 10 & 29873 & 29882 \\
\hline mono- & $\mathrm{T}$ & 10 & 46703 & 46712 \\
\hline mono- & $\mathrm{T}$ & 10 & 47865 & 47874 \\
\hline mono- & $\mathrm{T}$ & 10 & 56400 & 56409 \\
\hline mono- & $\mathrm{T}$ & 10 & 57552 & 57561 \\
\hline mono- & $\mathrm{T}$ & 10 & 86976 & 86985 \\
\hline mono- & $\mathrm{T}$ & 10 & 94469 & 94478 \\
\hline mono- & $\mathrm{T}$ & 10 & 99146 & 99155 \\
\hline mono- & $\mathrm{T}$ & 11 & 16200 & 16210 \\
\hline mono- & $\mathrm{T}$ & 11 & 25885 & 25895 \\
\hline mono- & $\mathrm{T}$ & 11 & 40958 & 40968 \\
\hline mono- & $\mathrm{T}$ & 11 & 50459 & 50469 \\
\hline mono- & $\mathrm{T}$ & 11 & 58416 & 58426 \\
\hline mono- & $\mathrm{T}$ & 11 & 95793 & 95803 \\
\hline mono- & $\mathrm{T}$ & 12 & 17608 & 17619 \\
\hline & & & & \\
\hline
\end{tabular}




\begin{tabular}{|c|c|c|c|c|}
\hline mono- & $T$ & 12 & 100200 & 100211 \\
\hline mono- & $T$ & 15 & 11233 & 11247 \\
\hline di- & AT & 5 & 32938 & 32947 \\
\hline di- & AT & 5 & 54921 & 54930 \\
\hline di- & AT & 6 & 14278 & 14289 \\
\hline di- & AT & 6 & 14298 & 14309 \\
\hline di- & AT & 6 & 59230 & 59241 \\
\hline di- & AT & 7 & 70407 & 70420 \\
\hline di- & TA & 5 & 195 & 204 \\
\hline di- & TA & 5 & 279 & 288 \\
\hline di- & $\mathrm{TA}$ & 5 & 466 & 475 \\
\hline di- & TA & 5 & 27730 & 27739 \\
\hline di- & TA & 5 & 41770 & 41779 \\
\hline di- & TA & 5 & 44628 & 44637 \\
\hline di- & $\mathrm{TA}$ & 5 & 62826 & 62835 \\
\hline di- & TA & 5 & 68954 & 68963 \\
\hline di- & TA & 5 & 69190 & 69199 \\
\hline di- & TA & 6 & 12557 & 12568 \\
\hline di- & TA & 6 & 86244 & 86255 \\
\hline di- & $\mathrm{TA}$ & 6 & 94457 & 94468 \\
\hline di- & TA & 7 & 10767 & 10780 \\
\hline di- & TA & 7 & 19813 & 19826 \\
\hline di- & TA & 7 & 25871 & 25884 \\
\hline di- & TA & 7 & 28304 & 28317 \\
\hline di- & $\mathrm{TA}$ & 7 & 29340 & 29353 \\
\hline di- & TA & 7 & 41786 & 41799 \\
\hline di- & TA & 8 & 57533 & 57548 \\
\hline di- & TA & 8 & 69397 & 69412 \\
\hline di- & TA & 10 & 100045 & 100064 \\
\hline di- & $\mathrm{TA}$ & 11 & 72289 & 72310 \\
\hline tri- & TTA & 4 & 70696 & 70707 \\
\hline tetra- & AATA & 3 & 54140 & 54151 \\
\hline tetra- & ATAA & 3 & 25162 & 25173 \\
\hline tetra- & ATAG & 3 & 10865 & 10876 \\
\hline tetra- & ATTT & 3 & 69685 & 69696 \\
\hline tetra- & CATA & 3 & 25129 & 25140 \\
\hline tetra- & TACC & 3 & 76426 & 76437 \\
\hline tetra- & TAGA & 3 & 85926 & 85937 \\
\hline penta- & AACAA & 3 & 54704 & 54718 \\
\hline
\end{tabular}




\begin{tabular}{|l|l|l|l|l|}
\hline penta- & AAGAA & 3 & 75527 & 75541 \\
\hline
\end{tabular}

